Student Success

ISSN: 2205-0795

Volume 10, Issue 1, pp. 131-139

March 2019

\title{
Preliminary impact of DegreePlus: An institutional program to provide transferable skill development through extracurricular activities. A Practice Report
}

\author{
Carmen L. Huffman, April C. Tallant and Shawna C. Young \\ Western Carolina University, Cullowhee, North Carolina, United States
}

\begin{abstract}
DegreePlus is a recently developed program at Western Carolina University (WCU) that aims to develop transferable skills, including professionalism, cultural responsiveness, leadership and teamwork, in students via their participation in extracurricular activities. A mixed-methods study that included focus groups and a survey was used to identify the preliminary impacts of the program. Researchers found that students view the program as a supportive initiative to help them prepare for their future and meet their career goals. Students also perceive that they are learning the targeted skills and are able to apply them to a limited extent. Finally, students view the program as a means of connecting to their university community. We anticipate that student participation in this program may assist with other institutional goals, such as retention and student success, as many of the impacts from the program align with principles that support these objectives.
\end{abstract}

Please cite this article as:

Huffman, C. L., Tallant, A. C., \& Young S. C. (2019). Preliminary impact of DegreePlus: An institutional program to provide transferable skill development through extracurricular activities. A Practice Report. Student Success, 10(1), 131-139. doi: 10.5204/ssj.v10i1.1094

This practice report has been accepted for publication in Student Success. Please see the Editorial Policies under the 'About' section of the Journal website for further information.

Student Success: A journal exploring the experiences of students in tertiary education

() $(6$ articles are free to use, with proper attribution. ISSN: 2205-0795 


\section{Introduction}

DegreePlus (Western Carolina University, 2018) is a program designed to provide transferable skill development to students at Western Carolina University through their participation in designated extracurricular activities. The program was developed as a Quality Enhancement Plan for the 2017 reaffirmation of accreditation by the Southern Association of Colleges and Schools Commission on Colleges. Much of the development of the program was inspired by the Student Transformative Learning Record (STLR) at the University of Central Oklahoma (Cunliff \& King, 2018; University of Central Oklahoma, 2018). STLR aims to instill six central tenets in their students, some of which are global and cultural competencies; leadership; and service learning and civic engagement. Similarly, DegreePlus aims to promote professionalism, cultural responsiveness, leadership and teamwork in student participants. The development of DegreePlus was prompted by a wealth of literature pointing to the need for such transferable skill development in today's college students. Calonge and Shah (2016) found there exists a "discontinuity between skills university graduates have when they graduate and the specific needs of employers" (p. 69). From a professional perspective, these transferable skills are important to students because of the evolving nature of jobs and because graduates often find employment that does not directly relate to their curricular majors (Baker \& Henson, 2010). A survey of both college students and employers by Hart Research Associates (2015) on behalf of the Association of American Colleges and Universities found that while some college students feel career-ready, employers disagree.

While faculty aim to deliver transferable skills through innovative curricula, Thompson, Clark, Walker and Whyatt (2013) point out that extracurricular activities may provide a better environment to teach transferable skills over academic courses. This concept aligns well with student involvement theory, which posits the greater the student's involvement in academics, extracurricular activities and interactions with faculty and staff, the greater their learning and personal development (Astin, 1984). In a survey by Baker and Henson (2010), students agreed that "extracurricular activity offered the best opportunities to develop teamwork, leadership, and other 'interpersonal skills'" (p. 65). Additionally, a recent survey by the National Association of Colleges and Employers (2016) points to a need for both transferable skills and extracurricular involvement. DegreePlus capitalises on these perceptions by delivering targeted skills through extracurricular events.

Beyond fostering transferable skills, extracurricular programing has the potential to shape the student experience and impact metrics of success for students and institutions alike. Kuh (1993) writes that involvement outside the classroom contributes to student personal development and learning. Some research has shown that students "evolve" more through a combination of their extracurricular and academic experiences. This evolution led to environments where increased learning occurred and students achieved more through the connections they made between the classroom and alternate learning environments (Kahu, 2013; Zepke, 2014). Research further indicates that involvement outside the classroom is related to persistence in some populations (Kuh, Kinzie, Buckley, Bridges, \& Hayek, 2006). Given the increasing pressures for institutions to retain students and meet graduation rate metrics, intentional, studentcentered extracurricular programing can be an integral part of a holistic retention strategy. These theories support the potential for DegreePlus to have extended benefits in areas related to overall student success. 


\section{Transferable skills}

DegreePlus aims to develop one or more of the following transferable skills in students: cultural responsiveness, leadership, and teamwork. To better define these broad terms, WCU used the literature (a sample of which is provided below) to develop a set of five student learning outcomes (SLOs) for each skill. Each outcome was written at the highest levels of Bloom's taxonomy (Bloom, 1956). While students will not necessarily meet the outcome by initially attending an event, they will build experience with the outcome that will enable them to achieve the outcome later. (See "Structure and incentivisation" below.)

Our term "cultural responsiveness" is similar to a definition of cultural competence as a "process of developing cultural awareness, knowledge, and skills" (Kratzke \& Bertolo, 2013, p. 1). Cultural responsiveness transitions beyond learning about diversity by also inferring interaction, reflection, and a call to action. These insights led to the following learning outcomes for the cultural responsiveness skill: Students will (a) demonstrate an awareness of key historical and current issues surrounding race, ethnicity, gender, social class, religion, sexual identity, ability, national origin, or other identities, (b) analyse one's own beliefs, traditions, norms, biases, and the differences/commonalities in relation to other's, (c) practice cultural sensitivity and respect when interacting with others, (d) engage in unfamiliar cultural spaces and experiences, and/or (e) identify resources and appropriate forms of advocacy to promote social justice and equity.

Although the idea of leadership has evolved over time, modern conceptions of leadership place value on "principles of collaboration, interpersonal effectiveness, process, ethical reciprocity, and affecting positive societal change" (Salisbury, Pascarella, Padgett, \& Blaich, 2012, p. 303). The following learning outcomes for leadership were incorporated into DegreePlus: Students will (a) demonstrate an understanding of leadership principles and behaviours of effective leaders, (b) utilise leadership styles in diverse contexts, (c) apply knowledge of conflict resolution in difficult situations, (d) generate and accept constructive feedback, and/or (e) define clear and actionable goals.

Definitions for professionalism vary widely but can include interpersonal skills, responsibility, integrity, as well as time and workload management (Wresch \& Pondell, 2015). In a survey by the Center for Professional Excellence at York College of Pennsylvania (2015), recent graduates listed strong communication skills, focus, punctuality/attentiveness, humility, and diligence as the most important components of professionalism. As such, the student learning outcomes for professionalism are as follows: Students will (a) apply appropriate communication methods to a variety of audiences, (b) recognise the importance of appropriate dress and professional image, (c) demonstrate ethical behavior in work-related contexts, (d) develop methods for building effective work relationships, and/or (e) demonstrate an awareness of industry specific culture and values.

While teamwork is another skill that can be difficult to define, Hughes and Jones (2011) describe five general components that feed into the concept of teamwork: a "collective identity", sharing of a common task, interdependence, specific roles of team members, and a "larger organisational context" (p. 54). The learning outcomes associated with teamwork are as follows: Students will (a) demonstrate the basics of team dynamics, (b) take responsibility for one's own role within a team, (c) utilise appropriate team communication skills, (d) treat others with respect and value others' contributions, and/or (e) contribute to the movement of a team toward a common goal. 


\section{How DegreePlus works}

\section{Structure and incentivisation}

Figure 1 illustrates the three-level structure of the voluntary DegreePlus program. The structure provides a scaffold for students to progress from observer to learner to practitioner. Students advance through three levels with incentives for completion at each level. Incentives include "swag" items, a formal notation on their academic transcript and a ceremonial event for completion of all three levels. Level 1 is the Experience and Exposure level. Students attend at least five DegreePlus events of their choice in one skill, earning points as a way to track their progress. These activities are designed to meet the SLOs at a lower Bloom's taxonomy level (Bloom, 1956), teaching and providing students with examples of skills. Level 2 is the Reflection and Articulation level. Students who have completed Level 1 attend "DegreePlus Day" (offered once per semester), which initiates Level 2. Trained faculty and staff mentors lead small group discussions to enable students to reflect on skills they've learned. Following the event, students articulate what they learned in a reflection paper, which the mentor evaluates as pass/rewrite. Students who have completed Level 2 can move to Level 3, Integration and Application. Students participate in a curricular, co-curricular or extracurricular experience that exemplifies their application and integration of the skill. On DegreePlus Day participants showcase their achievement of at least three SLOs for a particular skill by delivering a poster, video, or other creative presentation about this capstone experience. Positive evaluation of the demonstration signals completion of the program.

\section{Events and activities}

Hundreds of events and activities are hosted by faculty, professional staff, students, renowned scholars and guests each year at WCU. As at most institutions, interactive opportunities for students abound. These events range in size and duration and typically do not have additional requirements for students at the conclusion of the event or activity. Many of these activities are explicitly associated with some SLOs for the DegreePlus skills, and some can be modified to refocus on them. DegreePlus acts not only as a driver to increase participation in these events but also provides a way for students to make meaning of what they are learning by their participation. By indicating that an event supports a particular skill, students are alerted to important take-home messages and are given the language to articulate what they learned by participating. For example, prior to DegreePlus, students taking a Hula and Tahitian dance class viewed it as a dance-based exercise class. If asked what was learned, participants may have responded that it was a fun way to exercise. Now that DegreePlus has been established, our Campus Recreation and Wellness department has expanded the class to include instruction on the cultural significance of the dances. The incorporation of the cultural significance prepares students to achieve cultural responsiveness SLOs (a) and (d).

Campus event creators/sponsors have been asked to consider how their event aligns with the DegreePlus SLOs. To be included as a DegreePlus activity, the event must be extracurricular, be open to all or a significant subset of the student population, and introduce one or more of the DegreePlus skills 'to a great extent' (i.e. must put students on a path to achieve one or more of the SLOs for that skill). A DegreePlus administrator screens requests for inclusion. If an event meets the criteria, it becomes part of the DegreePlus schedule, and students earn points for attending. In the 20172018 academic year, the DegreePlus program was piloted with first year students in the Honors College, the Academic Success Program (a program for conditionally accepted freshmen), and the Leadership first year transition classes. 


\section{Degrag pLUS \\ DegreePlus is a 3-level voluntary experiential program which uses extr acurricular activities to help you obtain one or more transfer able skills. ( A transferable still is a skill that can be used in any car eer, no matter what you choose to do.) What's cool about Degr eePlus is you can go at your own pace and complete as many levels and skills as you want.}
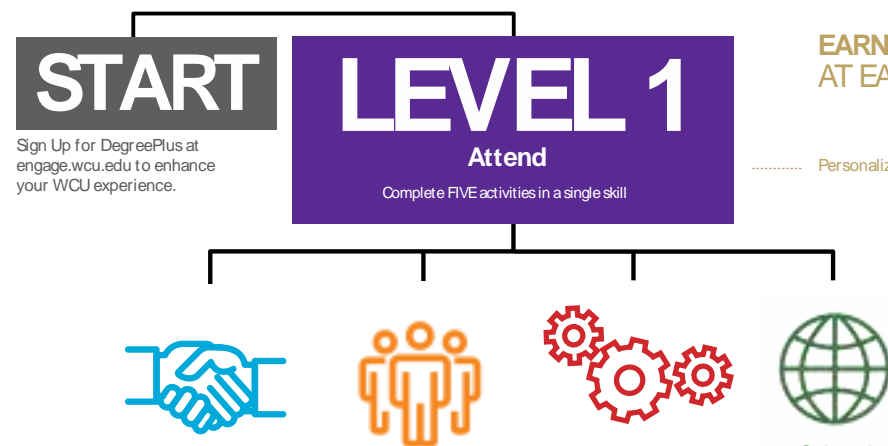

Cultural

Professionalism

Leadership

Teamwork

Responsiveness
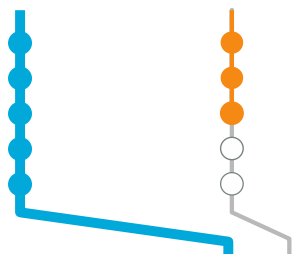

EARN REWARDS

AT EACH LEVE
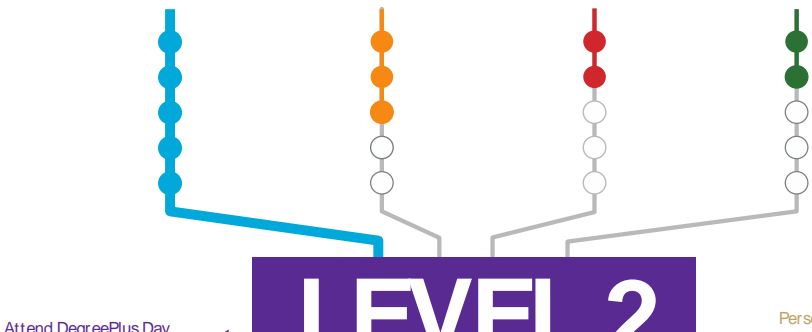

Attend DegreePlus Day

completing Level 1

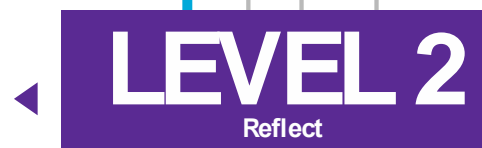

Submit a reflection on experiences in a single skill area

Personalized business

cards; notation on

academic transcript;

letter of accomplishment;

co-curricular tr anscript;

job shadowing

Financial support for

capst one project: plaque

of accomplishment;

experience of your choice

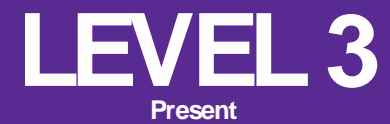

Present what you've learned at DegreePlus Day.

degreeplus.wcu.edu

Questions? Contact: Mati Newbold, Associate Director of DegreePlus | hmnewbold@ermali.wcu.edu | 828-227-7133

Center for Career and Professional Development | Undergraduate Studies

WZestern

Carolina

GUNIVESITY

Figure 1. Infographic to illustrate the three-level structure of the DegreePlus program. 
Other students outside of these groups were welcome to participate but were not provided with targeted marketing to encourage participation. Also, while we piloted the program with first year students, students are able to opt in to DegreePlus at any point of their academic career. In the pilot year, 93 events were offered to support either the professionalism skill or the cultural responsiveness skill. The following are examples of those program offerings:

Hire Attire Fashion Show - This was a large, interactive event in which students learned about appropriate dress for interviews and the workplace by observing other students modeling appropriate and inappropriate attire. This was a popular event with close to 265 attendees. Students found the content entertaining and accessible. This event targeted SLO (b) for the professionalism skill.

Workplace Etiquette - This workshop explored the "dos and don'ts" of working in a professional office space, including respecting others' personal space, lunchroom etiquette, and effective communication strategies. Twentyseven students attended this event, which targeted SLOs (a) and (d) for the professionalism skill.

Tunnel of Oppression - The Tunnel of Oppression is a two-day event which draws over 350 participants each semester. The event is an immersive experience which allows participants to consider the impact of various cultural issues such as racism, sexism, sexual slavery and the like. The program draws a mix of students interested in the cultural questions asked by the event and other students whose attendance has been incentivised by their professors promising class credit. The program targets SLOs (a), (b), (d) and (e) for the cultural responsiveness skill.

SafeZone Training - This training educates participants about the history and issues pertaining to sexuality and gender identity. This two-part, four-hour training is open to students and university employees. Participation in the trainings varies from five to sixteen attendees. At the completion of the training, participants receive a SafeZone certificate. The program targets all the SLOs for the cultural responsiveness skill.

\section{Preliminary impacts}

Impacts of participation in DegreePlus on student development were assessed in two ways: focus groups and surveys. Focus group conversations were held mid-way through the pilot year. Students who had given consent to share their participation data were invited to participate in the focus group study. These students were classified into two separate focus groups: the low participation group included students who attended less than three DegreePlus events, and the high participation group included students who attended three or more DegreePlus events. Each group received separate invitations to separate focus group sessions so that each focus group would be aligned according to students' level of participation in DegreePlus. In total, eight students participated in five focus group sessions (five in the low participation group and three in high participation group). Two questions addressed how the program impacted the students: (1) How did your participation in DegreePlus impact you? (2) How are you using what you learned in your DegreePlus participation? Notes from each session were compiled and researchers identified themes from responses.

Researchers found that both focus groups genuinely appreciated the opportunity to practice "adulting", but their motivation for participating varied. Students in the low participation focus group were interested in DegreePlus because they were looking for something to do, while students in the high participation focus group recognised the impact 
the program might have on their future. Focus group conversations suggest that for students who participated, DegreePlus has prompted them to start planning for their future. Students in the low participation focus group gained an awareness or understanding of targeted skills but were not able to apply them. However, students in the high participation focus group were able to clearly recall the events they had attended, could relate them to learning outcomes for the targeted skill, and cited specific examples of how they put them to use. For example, one individual attended a workplace behaviour event at which he learned how to carefully use "I" vs. "you" statements. He added, "I used it with my roommate because we were having problems".

Focus group findings helped us to craft a multiple choice and Likert format survey that was distributed to students who attended at least one DegreePlus event and any other students that were designated as pilot participants but did not attend any events. There were 86 responses to the survey. Upon omission of duplicates, untraceable students and non-participants, the final number of respondents was 33 .

Survey results complemented findings from the focus group study. For example, about a quarter of respondents indicated that DegreePlus had "a lot" or "a great deal" of impact on their "ability to reach their goals" (24\%), their "resourcefulness" (27\%), and "the way they think" (27\%). About half of students reported DegreePlus impacted their "ability to apply what they've learned" at least a moderate amount, and $42 \%$ reported that DegreePlus has "impacted their behavior" at least a moderate amount. At least $70 \%$ of survey respondents reported that DegreePlus made both "being competitive for current or future employment" and "feeling like [they] are preparing for life after graduation" easier. Also, $82 \%$ of students felt that DegreePlus had impacted their "ability to reach [their] goals" at least a little. This data suggests that the student experience is in alignment with the intentions of the DegreePlus program.

DegreePlus also appears to help students make connections. According to survey results, a majority reported that DegreePlus made it easier or much easier for them to "fit in at the university" (55\%); find "connections between [their] classes and [their] out of classroom activities" (61\%); connect "with professors or staff" (70\%); and to "find activities that are meaningful" (61\%). These preliminary results suggest that students view DegreePlus as a way to prepare for their future and make themselves marketable. Furthermore, the results show that DegreePlus concepts are being applied to the way they think and behave and that the program is helping students to fit in and make connections. These findings suggest an added benefit of connecting with the institution beyond simply gaining transferable skills.

\section{Conclusions}

DegreePlus, a program grounded in theory, career development literature and employer expectations, aims to make students careerready by developing transferable skills through their participation in extracurricular experiences. Despite the limitations of a small sample for our mixed methods study, preliminary findings show that DegreePlus is successfully meeting its goal of developing these skills in students. We observed that student participants are interested in preparing for their future and view DegreePlus as a way to be more competitive when they graduate. Surveys showed an impact on self-reported resourcefulness, thinking and behaviour. Additionally, participants reported a feeling of being connected to the university and faculty and staff, an important factor in student persistence and retention.

One of the main takeaways from our research is that DegreePlus provides the structure 
necessary to help students organise and make meaning of what seem like disparate activities. For other institutions seeking to help students make such connections, using an umbrella structure similar to DegreePlus, but befitting to their own community, may be of benefit. As DegreePlus is still in its beginning stages, we look to focus on evaluating and increasing campus buy-in in general, faculty perception of DegreePlus involvement in their "personalised" events, and exploring why events in particular skill areas have not been as popular (e.g. teamwork and leadership). Future research will continue to focus on the impact of DegreePlus on students in both the short- and long-term. Furthermore, research is needed to determine the impact and implications for faculty and staff who host DegreePlus events, the institution as a whole and ultimately, employers who hire WCU graduates.

\section{Acknowledgements}

The authors thank Arthur Salido, Theresa Cruz Paul and Marti Newbold for their work in the development and implementation of DegreePlus, Drew Virtue for assistance with the background literature, Kong Chen for review of the manuscript and guidance in the analysis, and the SACSCOC QEP review team, led by Jeff King, for thoughtful feedback of the program.

\section{References}

Astin, A. W. (1984). Student involvement: A developmental theory for higher education. Journal of College Student Personnel, 40, 518-529.

Baker, G., \& Henson, D. (2010). Promoting employability skills development in a research-intensive university. Education + Training, 52(1), 62-75. https://doi.org/10.1108/00400911011017681

Bloom, B. S. (1956). Taxonomy of educational objectives, handbook I: The cognitive domain. New York: David McKay Co., Inc.
Calonge, D. S., \& Shah, M. A. (2016). MO0Cs, graduate skills gaps, and employability: A qualitative systematic review of the literature. The International Review of Research in Open and Distributed Learning, 17(5), 69. https://doi.org/10.19173/irrodl.v17i5.2675

Center for Professional Excellence at York College of Pennsylvania. (2015). National professionalism survey recent college graduates report. Retrieved from https://www.ycp.edu/media/yorkwebsite/cpe/2015-National-ProfessionalismSurvey---Recent-College-Graduates-Report.pdf

Cunliff, E., \& King, J. (2018). Institutionalizing transformative learning: The trees, then the forest, then the realization. Metropolitan Universities, 29(3). https://doi.org/10.18060/22407

Hart Research Associates. (2015). Falling short? College learning and career success. Retrieved from https://www.aacu.org/sites/default/files/files/LEA

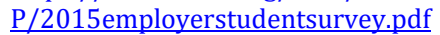

Hughes, R. L., \& Jones, S. K. (2011). Developing and assessing college student teamwork skills. New Directions for Institutional Research, 2011(149), 53-64. https://doi.org/10.1002/ir.380

Kahu, E. R. (2013). Framing student engagement in higher education. Studies in Higher Education, 38(5), 758773. https://doi.org/10.1080/03075079.2011.598505

Kratzke, C., \& Bertolo, M. (2013). Enhancing students' cultural competence using cross-cultural experiential learning. Journal of Cultural Diversity, 20(3), 107-111.

Kuh, G. D. (1993). In their own words: What students learn outside the classroom. American Educational Research Journal, 30(2), 277-304. https://doi.org/10.3102/00028312030002277

Kuh, G. D., Kinzie, J., Buckley, J. A., Bridges, B. K., \& Hayek, J. C. (2006, November). What matters to student success: A review of the literature. Paper presented at National Symposium on Postsecondary Student Success: Spearheading a dialog on Student Success. Washington DC. Retrieved from https://nces.ed.gov/npec/pdf/kuh team report.pdf

National Association of Colleges and Employers. (2016). Job outlook 2016: Attributes employers want to see on new college graduates' resumes. Retrieved from http://www.naceweb.org/s11182015/employerslook-for-in-new-hires.aspx

Salisbury, M. H., Pascarella, E. T., Padgett, R. D., \& Blaich, C. (2012). The effects of work on leadership development among first-year college students. Journal of College Student Development, 53(2), 300324. https://doi.org/10.1353/csd.2012.0021

Thompson, L. J., Clark, G., Walker, M., \& Whyatt, J. D. (2013). 'It's just like an extra string to your bow': Exploring higher education students' perceptions and 
experiences of extracurricular activity and employability. Active Learning in Higher Education, 14(2), 135-147. https://doi.org/10.1177/1469787413481129

University of Central Oklahoma. (2018). Student Transformative Learning Record. Retrieved from http://sites.uco.edu/central/tl/stlr/

Western Carolina University. (2018). DegreePlus. Retrieved from http://degreeplus.wcu.edu

Wresch, W., \& Pondell, J. (2015). Assessing cocurricular impacts on the development of business student professionalism: Supporting rites of passage. Journal of Education for Business, 90(3), 113-118. https://doi.org/10.1080/08832323.2014.988202

Zepke, N. (2014). Student engagement research in higher education: questioning an academic orthodoxy. Teaching in Higher Education, 19(6), 697-708. https://doi.org/10.1080/13562517.2014.901956 